\title{
APPROACH TO DESIGN SEQUENCE OF FIELD MELLIFEROUS CROPS TAKING INTO ACCOUNT USE OF AGRICULTURAL MACHINERY
}

\author{
Atanas Atanasov, Chavdar Vezirov \\ University of Ruse, Bulgaria \\ aatanasov@uni-ruse.bg, vezirov@uni-ruse.bg
}

\begin{abstract}
An approach for mutually beneficial solving the issues of providing melliferous plants for honey bees and optimizing the necessary equipment and its use is presented. The plants must be included in appropriate crop rotations and pollinated by bees. To ensure strong bee colonies, field crops, varieties and hybrids with high potential nectar yields, overlapping flowering periods, with different vegetation durations and different sowing dates are offered. At the same time, appropriate land management projects take into account climatic and meteorological conditions, too. Possible solutions are illustrated with graphs of expected nectar productivity, need for machinery, staff, fuel in a production year. The effectiveness of the proposed approach is reported in two directions: on the one hand, the benefit for farmers growing agricultural crops is shown in terms of reducing the need for machinery, increasing the employment of service personnel for socially, economically and environmentally sustainable agriculture. On the other hand, the benefit for beekeepers corresponding area is expressed in providing pollen and nectar for bees throughout the honey harvest period, good stocking of bee colonies with honey, reduction of harmful effects of overpopulation with bee colonies, lower feeding costs, for transport and maintenance, high yields of bee products. The approach is suitable for application in flat-hilly areas with predominantly arable agricultural lands and, at the same time, with insignificant areas covered by forest and meadow flowering vegetation.
\end{abstract}

Keywords: melliferous crops, machinery, bee colonies.

\section{Introduction}

Honey bees are insects that play a crucial role in pollinating crops and maintaining balance in an ecosystem. A feeding behaviour of bees is closely related to the needs of colonies and the production of nectar and pollen from flowering plant species. The permanent access to sufficient quantity and quality of food resources is crucial for the strength and development of bee colonies. The specifics of the flowering forest and meadow vegetation, as well as the crop rotations with cultivated flowering plant species in the different regions, require an individual approach to the design of both the apiaries and the areas with agricultural crops and the resources for their cultivation. With well-developed bee families and optimal climatic factors, honey yield largely depends on the correct approach in the design of apiaries and the choice of crops in crop rotation.

The intensive agriculture is associated with excessive use of pesticides and mineral fertilizers, reducing the number of crops in crop rotation, monoculture, sowing hybrids with a short growing season, low nectar production potential, limits the finding of suitable places for apiaries. The overpopulation with bee colonies in certain areas and the unregulated design of apiaries has a significant impact on the production of bee and agricultural products.

Best practices in beekeeping and pollination management lead to increased crop yields [1]. Placing the beehives near to agricultural fields with flowering cultivated plant species, where honey yield largely depends on the correct design approach, is crucial for optimizing the efficiency of bees in pollination and production of bee products [2]. To optimize the number of bee colonies and apiary sites, there are mathematical models [3] that partially solve the problem of bee nutrition in overloading areas by choosing the best option from several available alternatives. An interesting solution for providing bee colonies with food resources is the creation of a "honey conveyor" of flowering cultivated vegetation throughout the active honey harvest season.

Compared to determining the number of hives and their required area for feeding, determining the necessary resources for mechanized cultivation and harvesting of plant products from the field is relatively more complicated. The difficulties follow from the need for many different equipment, areas, contractors, fertilizers, pesticides, etc. The most commonly proposed approach to the design of the machine-tractor fleet is based on heuristic methods and is very laborious [4]. In some Eastern European countries, it is proposed to determine the necessary equipment on the basis of the so-called reference tractor or using specific software [5-7]. Unfortunately, these methods are not suitable for small farms due to the high inaccuracy of input information, the use of aggregated economic indicators or the unavailability of relevant application programs. 
The aim of the present work is to find mutually beneficial solutions for beekeepers and farmers by continuously providing honey plants for bee colonies and optimizing the necessary equipment and resources for growing of the agricultural crops.

\section{Materials and methods}

In the flat hilly areas for the good supply of bee colonies with honey and pollen is of great importance the presence of the longer bee pasture throughout the active period of beekeeping. This can be achieved by supplementing crop rotations with cultivated species that bloom in periods of lack of pasture, providing a constant flow of pollen and nectar. Applying such an approach will lead to avoidance of stress in bee colonies due to lack of bee pasture, continuous egg-laying by the queen, reduced swarming instinct, the presence of a brood, hatching a young bee in late summer and early autumn, additional yield of honey, wintering strong bee colonies, reducing the cost of feeding bee colonies. We expect the use of such an approach to lead to some agro-technical advantages, such as improving soil fertility and reducing the harmful effects of the previous crop, less costs for plant protection measures and hence - reducing bee poisoning, increasing crop yields as a result of pollination and improved soil fertility.

Our approach includes the following main stages:

1. Determining the available existing resources, providing inflow of nectar and pollen for the bees in a given area;

2. Selection of additional flowering crops to expand crop rotation;

3. Calculation of the expected honey yield for the current year depending on the productive potential of crop rotations;

4. Determining the needs for resources in the cultivation of agricultural crops from crop rotations.

The approach is applied to an apiary of 200 hives from the Dadant-Blatt system located in a flat hilly region of Northeastern Bulgaria. The geographical location of the experimental apiary is $43^{\circ} 32^{\prime} 4.02$ "C N, $25^{\circ} 45^{\prime} 14.10^{\prime \prime} \mathrm{E}$ at an altitude of $222 \mathrm{~m}$. The data for the forest massifs of flowering species and the size of the areas with agricultural crops in the experimental zone were obtained by traversing the areas and determining their coordinates with GPS Ashtec AC12 and GEOSURF SIZE1000 software. All collected data on the location of areas with forest and cultivated crops are included in Google Earth professional and a digital map of the experimental areas has been created.

The calculation was made for five variants of crop rotations, of which four stimulations and one real, located with a radius of $3 \mathrm{~km}$ around the experimental apiary. The following variants of crop rotations are considered: Variant 1 Acacia (Robinia pseudoacacia) Lime (Tilia cordata); Variant 2 Acacia, Lime, Sunflower (Helianthus annuus L); Variant 3 Winter oilseed rape (Brassica napus), Acacia, Lime a; Variant 4 Winter oilseed rape, Acacia, Lime, Sunflower; Variant 5 Winter oilseed rape, Acacia, Alfalfa for seeds (Medicago sativa), Lime, Sunflower, Sesame (Sesamum indicum), Jerusalem artichoke (Helianthus tuberosus).

Depending on the time and duration of flowering of forest and cultivated plants, as well as their potential for nectar secretion, the following crops are proposed: Alfalfa for seeds (Medicago sativa), Sesame (Sesamum indicum), Jerusalem artichoke (Helianthus tuberosus), as complementary to crop rotation, shown in variant 5 .

In determining the expected yield of honey for one year depending on the productive potential of crop rotations, the method presented in [8] was used.

In Europe, a normal-sized colony consumes relatively 60-202 kg of honey per year [9]. Based on this rough estimation and assuming that all factors remain constant, to harvest $1 \mathrm{~kg}$ of surplus honey, the colony has to consume a further $1 \mathrm{~kg}$ of honey for survival, brood rearing, as fuel energy to for-agers. Based on this requirement $2 \mathrm{~kg}$ of honey will be required in order to harvest $1 \mathrm{~kg}$ of honey and $1 \mathrm{~kg}$ of honey for colony maintenance [10]. For the purpose of our calculations, we assume that $90 \mathrm{~kg}$ of honey per hive to maintain the vital activities in the bee family are sufficient. If the number of bee colonies is 200 and we plan to get about $50 \mathrm{~kg}$ of honey from a hive, we offer to add the following areas with flowering crops: Alfalfa for seeds -20 ha; Sesame - 20 ha; Jerusalem artichoke -10 ha.

In order to ensure the mechanized cultivation of honey crops, it is desirable to determine the needs for resources more precisely. First, the areas are determined according to the crops in the crop rotation. Then choose a tractor, taking into account the available brands, models and modifications and the 
possibility of replacing with others or buying new ones. If there are several possible combinations of tractors, the most suitable machines are determined for each. Criteria for this are proximity to the maximum possible forward speed for the operation and the degree of engine load at the desired quality of work. If this is not achieved, either the working width of the machines is changed (for example by removing working bodies, devices) or another machine is selected. The calculation procedure is described in more detail in [11]. The data obtained for shift productivity and specific fuel consumption are input to another calculation procedure. The criterion for a successful solution is to reduce the need for equipment and service staff. Resource utilization schedules are used to facilitate the evaluation of the decision. This method is presented in more detail in [12].

\section{Results and discussion}

The calculated expected yield of honey from a hive for the individual variants of crop rotations with increasing number of crops considered from left to right is shown in Fig.1.
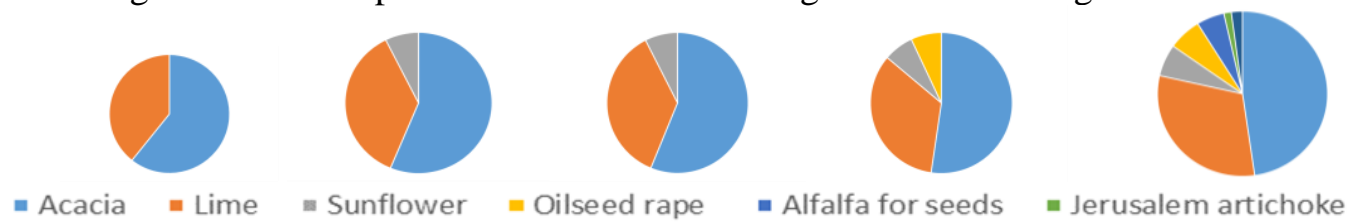

- Alfalfa for seeds

n Jerusalem artichoke

- Sesame

Fig 1. Change in the expected honey yield from per hive

From the calculations made, it was established in Fig. 1. that in all five variants of research of great importance on the yield of honey has forest vegetation of Acacia and Lime. In the first variant of calculation it was found that at an area of 90 ha of Acacia and 60 ha of Lime the total amount is $111.15 \mathrm{~kg}$, honey per hive, which is sufficient to maintain vital functions in the colony for the whole year and obtaining $21.15 \mathrm{~kg}$ of surplus honey per hive. A similar increase in yield by about $9 \mathrm{~kg}$ honey per hive is observed in the other three variants. Despite the high potential for honey yield from the studied crop rotations to be high enough to maintain the vital fictions of the colonies and the production of surplus honey, the actual yield is $21 \mathrm{~kg}$ of surplus honey per hive. If we assume that all other factors are constant, in the fifth variant of the study the total honey per hive is $141.4 \mathrm{~kg}$ and $51.5 \mathrm{~kg}$ of surplus honey per hive, which is the highest of all considered.

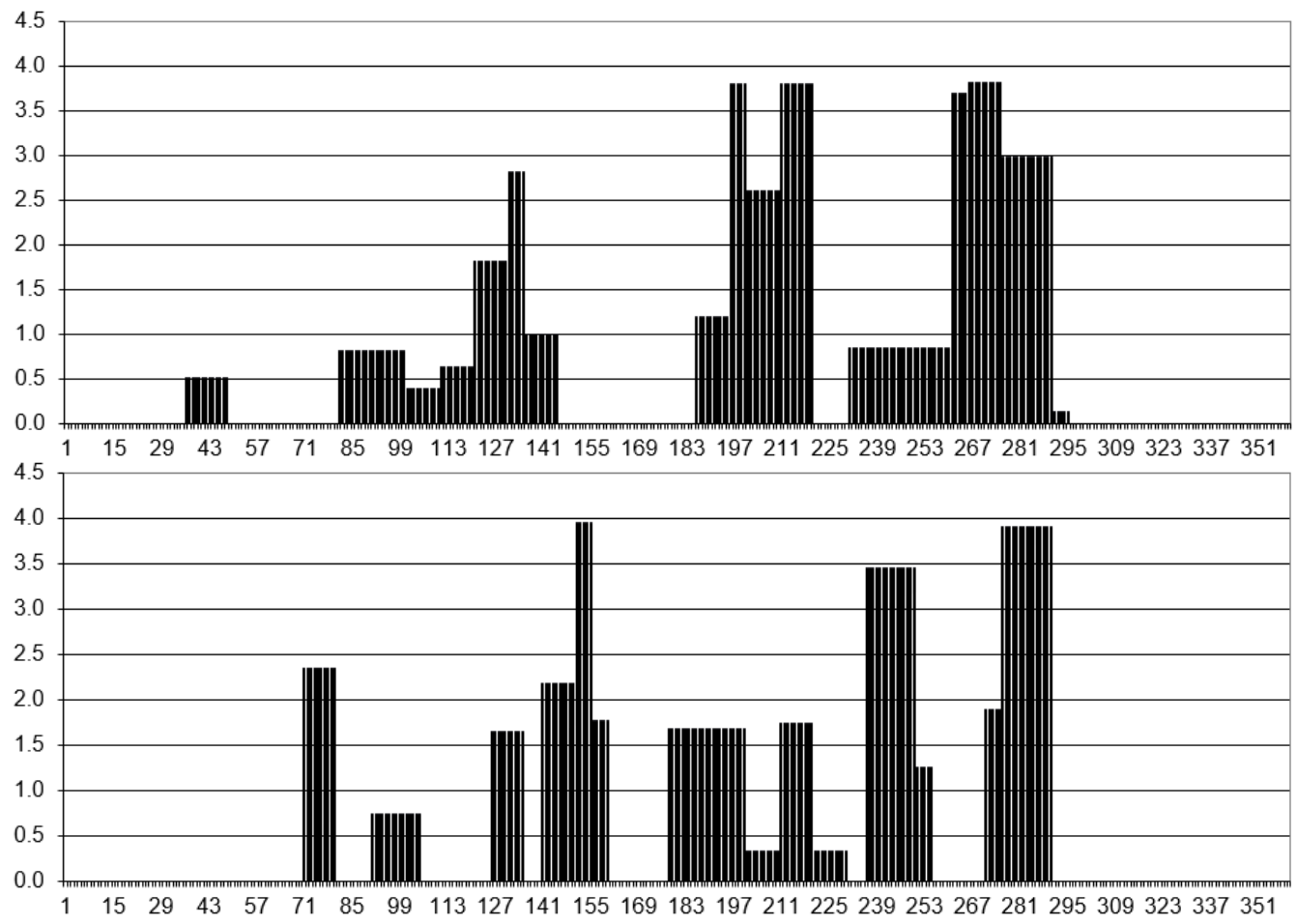

Fig. 2. Number of needed tractors towing class 3, type MFWD, $111 \mathrm{~kW}$ on vertical axis for monoculture farming during calendar year on horizontal axis. Above with 480 ha of wheat, 422 per tractor, below with 480 ha of corn, 401 hours per tractor 
In order to get the maximum profit from the whole area, a need for resources in monoculture agriculture is first determined. Wheat and maize are suitable for the conditions of the area where the apiary is located. Regardless of whether they are grown for food grain or fodder, four of the selected tractors are needed - Fig. 2.

That is why another solution was evaluated - Fig. 3. As a result, the need for tractors was reduced by one, and the tractor's employment during the working field season became more even. In order to use the available two less powerful tractors, it was planned to include more alfalfa and sesame - Fig. 4 .

It turned out to be possible to add another crop - Jerusalem artichoke, without increasing the need for equipment, except for that for harvesting. At the same time, enough work is provided for tractors' drivers - Fig. 5. It is smaller than for tractors, as tractors' drivers have to work in some periods of two or three shifts.

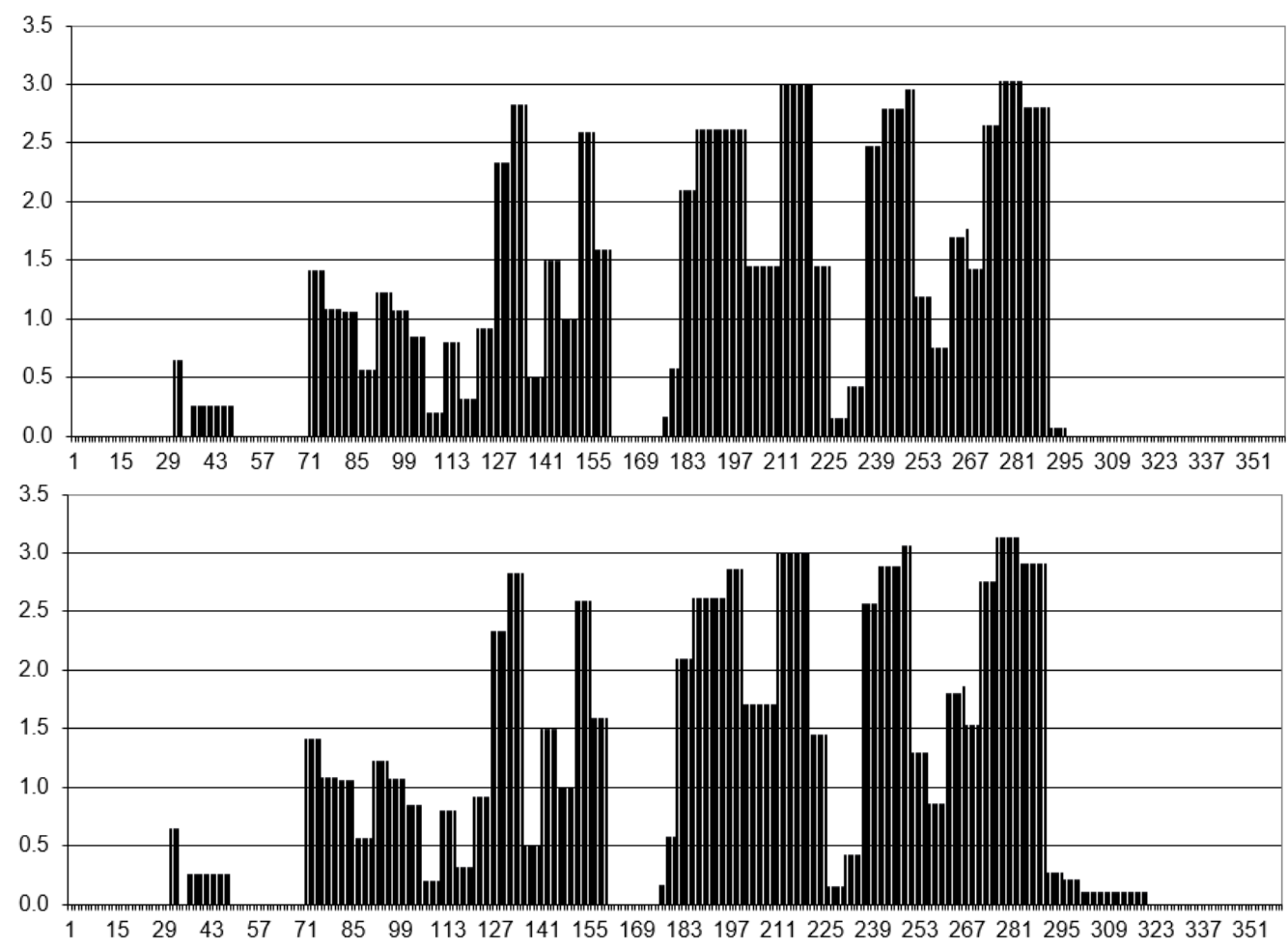

Fig. 3. Number of needed tractors towing class 3, type MFWD, $111 \mathrm{~kW}$ on vertical axis during calendar year on horizontal axis. Above with 240 ha of wheat, 120 ha of corn, sunflower and rapeseed of 60 ha 564 hours, below with addition of alfalfa and sesame for grain of 20 ha and 10 ha of Jerusalem artichoke 542 hours (of the last three crops only heavy tillage)

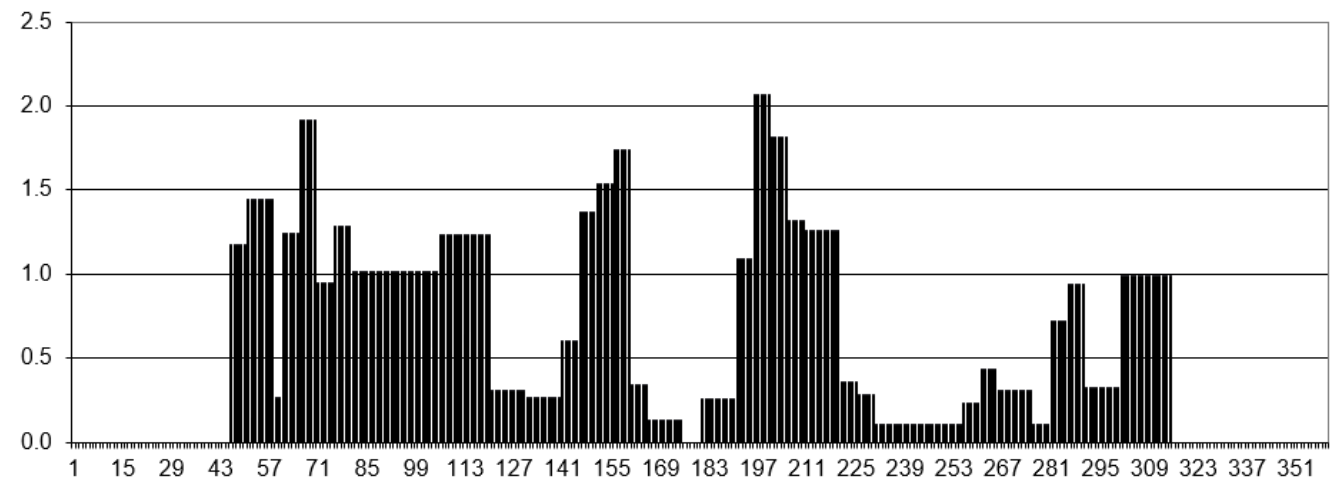

Fig. 4. Number of needed tractors towing class 1.4, type MFWD, $47.5 \mathrm{~kW}$ on vertical axis during calendar year on horizontal axis for alfalfa and sesame for grain of 20 ha and 10 ha of Jerusalem artichoke, 360 hours per tractor 
Unfortunately, the seasonality of agricultural operations and their different energy intensity lead to different fuel consumption. In the autumn, as seen in Fig. 6, the need for fuel is greatest. The proposed decision also be assumed that around $80 \%$ of transport during this period would be from non-agricultural vehicles. The reason is the long-distance transportation of grain off the farm.

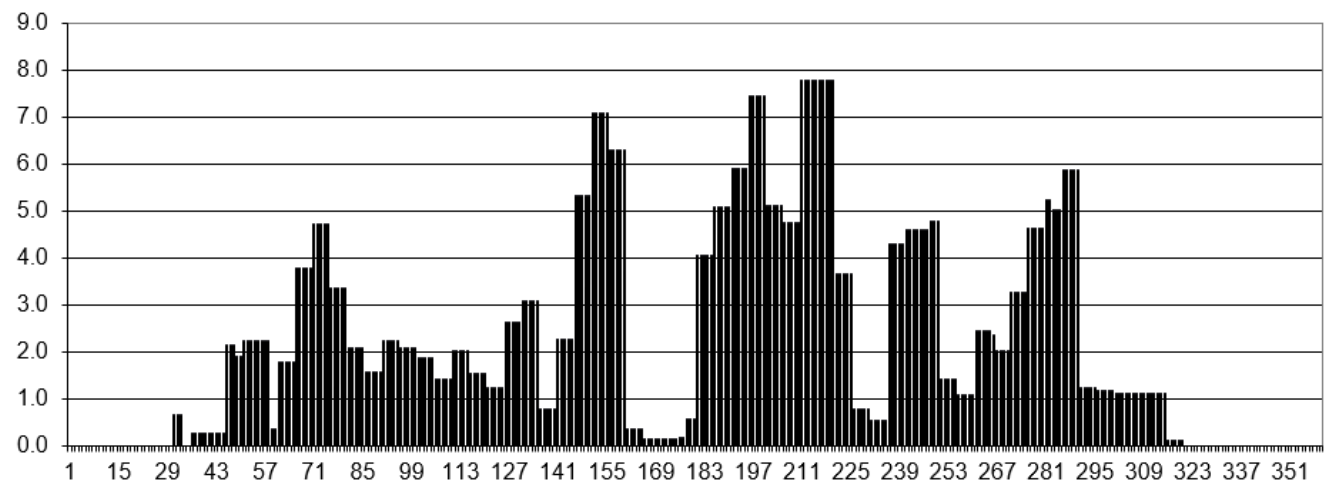

Fig. 5. Number of needed tractor drivers on vertical axis during calendar year on horizontal axis for two four-field crop rotations with 240 ha of wheat, 120 ha of maize, sunflower and rapeseed on 60 ha of alfalfa and sesame for grain on 20 ha and 10 ha of Jerusalem artichoke 432 hours per tractor driver

Unfortunately, the seasonality of agricultural operations and their different energy intensity lead to different fuel consumption. In the autumn, as seen in Fig. 6, the need for fuel is greatest. The proposed decision also be assumed that around $80 \%$ of transport during this period would be from non-agricultural vehicles. The reason is the long-distance transportation of grain off the farm.

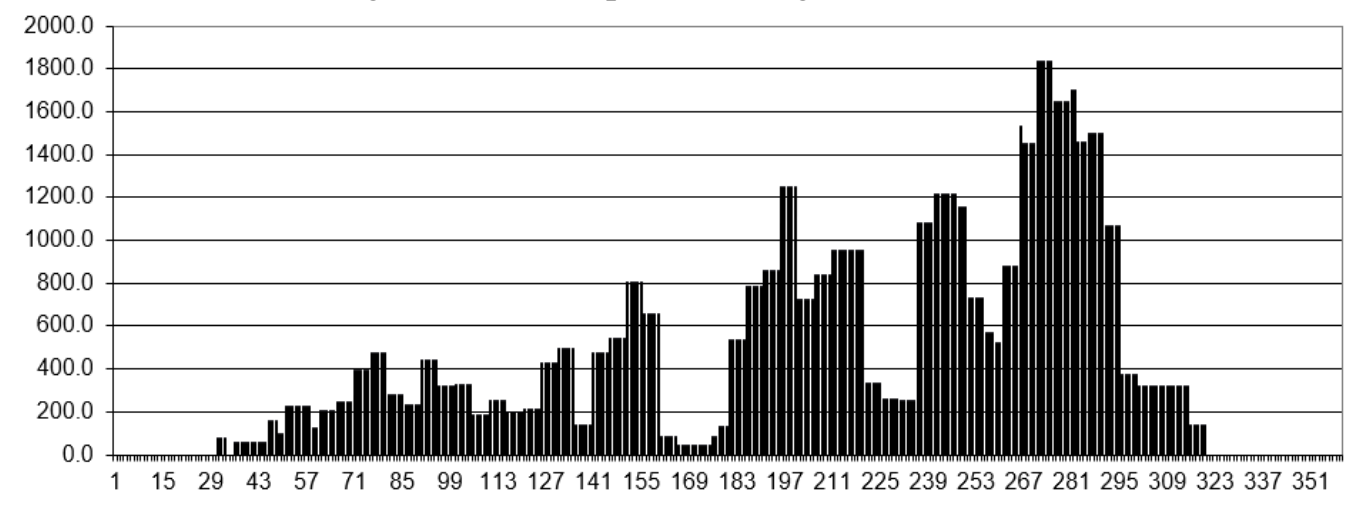

Fig. 6. Daily fuel requirement in kg on vertical axis during calendar year on horizontal axis for two four-field crop rotations for 240 ha of wheat, 120 ha of maize, sunflower and rapeseed of $60 \mathrm{ha}$, alfalfa and sesame for grain of 20 ha and $10 \mathrm{ha}$ of Jerusalem artichoke

The figures above make it possible to visually assess the decisions made in relation to the need for basic resources. Such diagrams are displayed automatically for other machines and this gives a complete picture of the need for long-term and short-term tangible assets, machine operators, workers and draft animals.

In addition, the resource of managed land was determined not only by the number and cultivated crops. The choice of specific fields was taken into account in the direction and strength of the prevailing winds during the flowering of the plants. Restrictions on the activity of bees in the same periods were also taken into account due to the air temperature, precipitation and again the direction and strength of the wind and the location of the hives. Naturally, the different location of the flowering vegetation over the years, according to the rotation of the crops in the fields, requires a corresponding location of the apiary.

At the same time, the selected crops provide a sufficient amount of honey not only for sale, but also for the maintenance of bees. It is clear that strong bee colonies also have a greater potential for pollination, including of agricultural crops. 
Such a multifaceted approach is appropriate due to the very large and complex set of possible solutions and situations. It is practically impossible to describe the system of agricultural and wild plants, pollinating insects, technical and executive resources. Another requirement is for integer solutions, especially important for small farms. This feature of determining the required flowering plants as a species and sequence requires the approach to be based on heuristic principles.

\section{Conclusions}

Creating a sequence of overlapping flowering crops to provide long period with enough nectar for honey bees and adding it with other cultivated plants in appropriate crop rotations may give mutual result for beekeeping and crop production. Including more melliferous plants is a good prerequisite for a growth of honey from $111 \mathrm{~kg}$ to $132 \mathrm{~kg}$ per hive per year. At the same time, annual employment per tractor driver increases from 411 to 453 hours and annual load per tractor of towing class 3, type MFWD, $111 \mathrm{~kW}$ increases from 401 to 542 hours. Other effect may be better colony vitality and higher crop yields because of better plant pollination.

\section{Acknowledgements}

This research is supported by Bulgarian National Science Fund under Project KP-06-PN 46-7 "Design and research of fundamental technologies and methods for precision apiculture".

\section{References}

[1] Geslina B., Aizenc M.A., Garciad N., Pereirae A.J., Vaissièref B.E., Garibaldia L.A. The impact of honey bee colony quality on crop yield and farmers' profit in apples and pears, Agriculture, Ecosystems and Environment 248 (2017) pp. 153-161. DOI: 10.1016/j.agee.2017.07.035.

[2] Saritha R., Vinod Chandra S. S. Multi-Dimensional Honey Bee Foraging Algorithm Based on Optimal Energy Consumption, J. Inst. Eng. India Ser. B (October 2017) 98(5): pp. 527-531, DOI: 10.1007/s40031-017-0294-4.

[3] Aderinto Y.O., A. Azagbaekwue, O.M. Bamigbola, M. O. Oke, A. A. Obayomi, L. O. Salaudeen, T.O. Aliu Optimization of Honey Bee Production, International journal of mathematical models and methods in applied sciences, Volume 14, 2020, DOI: 10.46300/9101.2020.14.13.

[4] Зангиев А. А., Шпилько А. В., Левшин А. Г. Эксплуатация машинно-тракторного парка. (Exploitation of machine and tractor fleet) - М., Колос, 2013. (In Russian).

[5] Cupiał M. and Kowalczyk Z. Optimization of Selection of the Machinery Park in Sustainable Agriculture. 2020. [online][21.03.2021] Available at: https://www.researchgate.net/publication/339422097

[6] Dokin B. D. et al. Process approach for modeling of machine and tractor fleet structure. Journal of Physics Conference Series 1015(3): 03200. May, 2018.

[7] Zubina V., Kutyrev A. Development of a software package for the tractor fleet formation in agricultural organizations. MATEC Web of Conferences 298, 00102. 2019. [online][21.03.2021] Available at: https://www.matecconferences.org/articles/matecconf/pdf/2019/47/matecconf_icmtmte18_00102.pdf.

[8] Zhelyazkov P., Atanasov A., Hristakov I. Study on the honey productive potential of the bee forage species in Northeast part of Bulgaria in Silistra region, X International Scientific Symposium FMPMSA 2019, pp. 183-188.

[9] Seeley, T.D., Camazine, S., Sneyd, J., 1991. Collective decision making in honey bees: how colonies choose among nectar sources. Behav.Ecol. Sociobiol. 28, pp. 277-290.

[10] Al-Ghamdi, A., Adgaba, N., Getachew, A., \& Tadesse, Y. New approach for determination of an optimum honeybee colony's carrying capacity based on productivity and nectar secretion potential of bee forage species, Saudi Journal of Biological Sciences, Volume 23, Issue 1, 2016, pp. 92-100.

[11] Vezirov C., Atanasov A., Vladut V. Calculation of field capacity and fuel consumption of mobile machinery with bunkers, tanks or other containers for agricultural goods, Journal INMATEH Agricultural Engineering, vol. 63, No. 1, 2021, pp. 19-28.

[12] Vezirov C. et al. Determination of resources necessities in agricultural production. Proceedings of the 41. International symposium on Agricultural engineering, Actual Tasks on Agricultural Engineering, Opatija, 19-22. February, 2013, pp. 24-33. 